\title{
Corrigendum: EEG Signal Complexity Is Reduced During Resting-State in Fragile X Syndrome
}

\begin{abstract}
Mélodie Proteau-Lemieux ${ }^{1,2 \dagger}$, Inga Sophia Knoth ${ }^{2 \dagger}$, Kristian Agbogba ${ }^{2}$, Valérie Côté ${ }^{2}$, Hazel Maridith Barlahan Biag ${ }^{3}$, Angela John Thurman ${ }^{3}$, Charles-Olivier Martin ${ }^{2}$, Anne-Marie Bélanger ${ }^{2}$, Cory Rosenfelt ${ }^{4}$, Flora Tassone ${ }^{3,5}$, Leonard J. Abbeduto ${ }^{3,6}$, Sébastien Jacquemont ${ }^{2,7}$, Randi Hagerman ${ }^{3}$, François Bolduc ${ }^{4}$, David Hess/ ${ }^{3,6}$, Andrea Schneider ${ }^{3,8}$ and Sarah Lippé ${ }^{1,2 *}$

${ }^{1}$ Department of Psychology, University of Montreal, Montreal, QC, Canada, ${ }^{2}$ Research Center of the Sainte-Justine University Hospital, Montreal, QC, Canada, ${ }^{3}$ University of California Davis Medical Investigation of Neurodevelopmental Disorders (MIND) Institute, Sacramento, CA, United States, ${ }^{4}$ Department of Pediatric Neurology, University of Alberta, Edmonton, AB, Canada, ${ }^{5}$ Department of Biochemistry and Molecular Medicine, University of California Davis School of Medicine, Sacramento, CA, United States, ${ }^{6}$ Department of Psychiatry and Behavioral Sciences, University of California Davis School of Medicine, Sacramento, CA, United States, ${ }^{7}$ Department of Pediatrics, University of Montreal, Montreal, QC, Canada, ${ }^{8}$ California North State University, College of Psychology, Rancho Cordova, CA, United States
\end{abstract}

Keywords: fragile $\mathrm{X}$ syndrome, hyperexcitability, EEG resting-state, signal complexity, multiscale entropy, alpha peak frequency, neurodevelopmental disorders, development

\section{OPEN ACCESS}

Edited and Reviewed by: Wenbin Guo,

Central South University, China

*Correspondence: Sarah Lippe

sarah.lippe@umontreal.ca

†These authors share first authorship

Specialty section

This article was submitted to Neuroimaging and Stimulation, a section of the journal Frontiers in Psychiatry

Received: 31 January 2022 Accepted: 02 February 2022 Published: 24 February 2022

Citation:

Proteau-Lemieux M, Knoth IS, Agbogba K, Côté V, Barlahan Biag HM, Thurman AJ, Martin C-O, Bélanger $A-M$, Rosenfelt $C$, Tassone $F$,

Abbeduto $L J$, Jacquemont $S$ Hagerman R, Bolduc F, Hessl D,

Schneider $A$ and Lippé S (2022) Corrigendum: EEG Signal Complexity Is Reduced During Resting-State in Fragile $X$ Syndrome Front. Psychiatry 13:867000 doi: 10.3389/fpsyt.2022.867000

\section{A Corrigendum on}

EEG Signal Complexity Is Reduced During Resting-State in Fragile X Syndrome by Proteau-Lemieux, M., Knoth, I. S., Agbogba, K., Côté, V., Barlahan Biag, H. M., Thurman, A. J., Martin, C-O., Bélanger, A-M., Rosenfelt, C., Tassone, F., Abbeduto, L. J., Jacquemont, S., Hagerman, R., Bolduc, F., Hessl, D., Schneider, A., and Lippé, S. (2021). Front. Psychiatry 12:716707. doi: $10.3389 /$ fpsyt.2021.716707

In the original article, there was an error. The abstract states that we compared 26 FXS participants with 7 neurotypical controls. This is incorrect. As correctly stated in the methods and result sections, we compared 26 FXS participants to 77 neurotypical controls.

A correction has been made to Methods section of the Abstract.

Methods: In this study, resting-state EEG power, including alpha peak frequency (APF) and theta/beta ratio (TBR), as well as signal complexity using multi-scale entropy (MSE) were compared between 26 FXS participants (ages 5-28 years), and 77 neurotypical (NT) controls with a similar age distribution. Subsequently a replication study was carried out, comparing our cohort to 19 FXS participants independently recorded at a different site.

The authors apologize for this error and state that this does not change the scientific conclusions of the article in any way. The original article has been updated.

Publisher's Note: All claims expressed in this article are solely those of the authors and do not necessarily represent those of their affiliated organizations, or those of the publisher, the editors and the reviewers. Any product that may be evaluated in this article, or claim that may be made by its manufacturer, is not guaranteed or endorsed by the publisher.

Copyright (c) 2022 Proteau-Lemieux, Knoth, Agbogba, Côté, Barlahan Biag, Thurman, Martin, Bélanger, Rosenfelt, Tassone, Abbeduto, Jacquemont, Hagerman, Bolduc, Hessl, Schneider and Lippé. This is an open-access article distributed under the terms of the Creative Commons Attribution License (CC BY). The use, distribution or reproduction in other forums is permitted, provided the original author(s) and the copyright owner(s) are credited and that the original publication in this journal is cited, in accordance with accepted academic practice. No use, distribution or reproduction is permitted which does not comply with these terms. 